\title{
An investigation on leadership styles in different cultures
}

\author{
Mahmoud Malmir ${ }^{a^{*}}$, Mohammad Javad Esfahani ${ }^{\mathrm{b}}$ and Mostafa Emamic
}

${ }^{a}$ Assistant Professor of Islamic Azad University, Khorasgan Branch (Esfahan), Khorasgan (Esfahan), Iran

${ }^{b}$ Department of Industrial Engineering, Young Researchers Club, Naragh Branch, Islamic Azad University, Naragh, Iran

${ }^{c}$ Young Researchers Club, Kermanshah Branch, Islamic Azad University, Kermanshah, Iran

C H R O N I C L E

Article history:

Received January 14, 2013

Received in revised format

18 April 2013

Accepted 20 April 2013

Available online

April 212013

Keywords:

Leadership style

Organizational culture

\section{A B S T R A C T}

During the past few years, there have been tremendous efforts on leadership style and various aspects of different leadership style. Some firms can achieve effective business performance by developing strong organizational culture and effective leadership while many studies indicate that firms can achieve effective business performance by developing strong organizational culture and effective leadership. This paper reviews recent advances on leadership style and various aspects of organizational cultures completed during the past few years. The paper concentrates on recently published articles appeared in the world.

\section{Introduction}

During the past few years, there have been tremendous efforts on leadership styles. Many people discuss different aspects of leadership style and their effects on organizations (Hofstede, 1980; Graen et al., 1997; Graen \& Hui, 1999; Markham, 2010). Bass (1977), for instance, discussed the universality in the transactional-transformational leadership paradigm. In other words, the same conception of phenomena and relationships is detected within the most organizations and cultures. Exceptions can be considered as a consequence of unusual attributes of the organizations or cultures.

In this paper, we review recent studies on leadership styles by looking into some empirical investigation accomplished in various countries and different applications. The study covers a wide range of empirical studies from the effect of leadership style on enterprise resource planning to differences on leadership style on various countries.

Corresponding author.

E-mail: dr.malmir1@gmail.com (M. Malmir)

(C) 2013 Growing Science Ltd. All rights reserved. doi: $10.5267 /$ j.msl.2013.04.021 


\section{Leadership}

Wilderom et al. (2012) investigated the combined impacts of charismatic leadership and organizational culture on perceived and objective company performance using a longitudinal design. They rated all employees of a large Dutch bank in 46 branches based on charismatic leadership, organizational culture in terms of work practices, as well as perceived organizational performance. They reported that charisma increased financial performance; however, culture did not. Culture and charisma were significantly associated with perceived performance, and culture and charisma were interrelated. However, they discussed that a longer time interval could be also necessary before the impacts of culture on financial performance become apparent.

$\mathrm{Bu}$ et al. (2007) performed an empirical investigation on acceptance of supervisory direction in typical workplace situations by comparing US, Taiwanese and PRC Employees. They reported the tendency to accept a supervisor's direction was influenced by peer consensus to a bigger extent among US employees than among Taiwanese and PRC employees. Compared with US and Taiwanese employees, PRC employees were more sensitive to a supervisory direction's consistency with company policies and less responsive to their own assessment of the direction's merit. In their study, both cultural traditions and modern developments appeared to impact employees' reaction to supervisory authority. Mills (2005) investigated the difference between Asian and American leadership styles.

Acar (2012) performed an investigation on organizational culture, leadership styles and organizational commitment in Turkish logistics industry. They explored the impacts of organizational culture and leadership styles on employees' commitment. According to their findings, there are some positive effects of leadership and organizational culture on the organizational commitment in context of logistics industry. Faris and Parry (2011) compared Islamic organizational leadership within a Western society. They examined the relationship between leadership, organizational culture and organizational effectiveness in Islamic organizations in Australia in the early years of the 21st century. They also investigated the contextual challenges faced by Islamic organizations in Western societies in that period. They concluded that the leadership of Islamic organizations was faced with the traditional leadership challenges found in the extant literature.

Kwantes and Boglarsky (2007) examined perceptions of which aspects of organizational culture were associated with leadership and personal effectiveness using archival data from Canada, Hong Kong, New Zealand, South Africa, the United Kingdom, and the United States. In their survey, organizational culture was perceived as being associated with both leadership effectiveness and personal effectiveness. They reported "the perceived relationship across samples was stronger between organizational culture and leadership effectiveness than between organizational culture and personal effectiveness".

Kim et al. (2011) presented some ideas to upgrade job performance and to improve organizational management by analyzing leadership perspectives and organizational cultures of radiological technologist organizations. They reported that radiological technologists stressed consensus most among the four kinds of organizational culture and regarded core transformational leadership as the right type of leadership. They also reported that transformational leadership had the highest impact on organizational effectiveness. Finally, they concluded that, as for the relationship between organizational culture and organizational effectiveness, a developmental culture could have the highest impact on organizational effectiveness, followed by a culture of consensus.

According to Zehir et al. (2011), firms can achieve effective business performance by developing strong organizational culture and effective leadership. Despite tremendous investigation on this issue, little empirical research has been devoted on the association between the three concepts. Zehir et al. (2011), in a comprehensive study, tried to fill this gap in the literature using the association between 
the leadership, culture and performance using the data collected from national and global firms with manufacturing, finance and telecommunication industries in Turkey.

Steyrer et al. (2008) investigated the impact of executive leadership behaviors on the organizational commitment (OC) of subordinate managers and the effect of the latter on measures of firm performance. They reported that desirable leadership behavior was positively associated with subordinates' OC, and that OC contributes to company performance, even when analyzed in association with crucial contextual variables.

Berson et al. (2006) reviewed theoretical and empirical work associated with the nexus of leadership with organizational learning. We build on the classic distinction between exploration and exploitation and the 4I framework of organizational learning (Crossan et al., 1999) to present previous research and offer research directions linking leadership constructs and processes of organizational learning at different levels of analysis. They discussed the mediating impact of organizational context and suggested future research directions.

Rajah et al. (2011) integrated research conducted during the past decade, which links with leadership style, behavior, and effectiveness, emotionality. They observed four running themes including emotional competencies of leaders, stress in leadership, contagion of positive and negative affect, and the impacts of leaders' emotions on outcomes like burnout and performance and summarized literature on potential mechanisms, which link with leadership and highlight directions for future research, emotionality.

Walumbwa et al. (2011) performed an empirical investigation on the link between ethical leadership and performance using some data from the People's Republic of China. They examined leadermember exchange (LMX), self-efficacy, and organizational identification as mediators of the ethical leadership to performance relationship and their results were consistent with social exchange, social learning, and social identity theories. They reported that ethical leadership was positively and significantly associated with employee performance as rated by their immediate supervisors and that this relationship was fully mediated by LMX, self-efficacy, and organizational identification, controlling for procedural fairness.

Aktaş et al. (2011) studied the relationship between organizational culture and organizational efficiency and the impact of stability or variability of internal and external environment on this relationship in an empirical study. They explained that organizational culture types were associated with some organizational efficiency dimensions. According to Jung et al. (2003) a wide range of factors are available to affect organizational innovation including top managers' leadership style. However, few studies have empirically investigated the link between this factor and innovation at the organizational level. They performed on the extant literature to present four hypotheses on how top managers' leadership styles directly and indirectly could influence their companies' innovation. They implemented a multisource approach to collect survey data from 32 Taiwanese firms in the electronics/telecommunications industry. Their findings supported a meaningful and positive link between a style of leadership labeled as "transformational" and organizational innovation. They also stated that transformational leadership had significant and positive relationship with both empowerment and an innovation-supporting organizational climate. The former was reported to have a substantial but negative relationship with organizational innovation, while the latter had a significant and positive relationship.

Zehir and Erdogan (2011) surveyed the relationship between organizational silence and leadership behavior in case of ethical leadership. They also examined the employee performance through these variables by performing a survey on 714 people who worked for national and multinational firms in Turkey to compare relationship between the factor analysis, reliability, correlations and regressions. They reported that all hypotheses were supported and positively related. According to Yuan and Lee 
(2011), leadership plays essential role on management function helping to maximize efficiency and reach organizational objectives. They performed an empirical survey on a theoretical model, which linked to different leadership types, organization cultures, employees and performance. Their result indicated significant differences between the employees' perceived leadership types, organization cultures, leadership performance and firm's background. Byrne and Bradley (2007) examined how personal and national cultures influence leadership style by examining culture's effect on leadership efficiency. They collected data on CEOs using Schwartz's framework, in three EU countries and stated some hypotheses, examined them and derived implications and conclusions. Shao et al. (2012) investigated the mediating impact of organizational culture and knowledge sharing on transformational leadership and enterprise resource planning systems success by performing an empirical study in China.

Menges et al. (2011) performed transformational leadership climate by investigating performance linkages, mechanisms, and boundary conditions at the organizational level. According to Tsui et al. (2006), both the functionalist and the attribution perspectives support a strong association between CEO leadership behavior and organizational culture. However, contingency perspective directs to the potential limits of the leader's capability to change or form an organization's culture. They aim for a deep understanding of when and why decoupling between CEO leadership behavior and organizational culture may happen. They also investigated this issue in a novel context, the People's Republic of China, where there was large variance on leader discretion in various types of firms. They conducted two survey studies and an interview investigation to unpack the nature of the relationship. They also offered some insights on both leadership and institutional factors, which could account for the decoupling between CEO leadership behavior and organizational cultural values.

Ke and Wei (2008) theorized how leadership could influence enterprise resource planning (ERP) implementation by fostering the desired organizational culture. They reported that ERP implementation success was positively associated with organizational culture along the dimensions of learning and development, participative decision making, power sharing, support and collaboration, and tolerance for risk and conflicts. They also identified the strategic and tactical actions top management could take to impact organizational culture and foster a culture conducive to ERP implementation.

\section{Summary}

This survey has covered recent advances on leadership style and its implementation on various context through empirical investigation. The review suggests that there are still tremendous opportunities for examining the effects of leadership style on performance of organizations.

\section{References}

Acar, A.Z. (2012). Organizational culture, leadership styles and organizational commitment in Turkish logistics industry. Procedia - Social and Behavioral Sciences, 58, 217-226.

Aktaş, E., Çiçek, I., \& Kıyak, M. (2011). The Effect Of Organizational Culture On Organizational Efficiency: The Moderating Role Of Organizational Environment and CEO Values. Procedia Social and Behavioral Sciences, 24, 1560-1573

Bass, B. M. (1997). Does the transactional-transformational leadership paradigm transcend organizational and national boundaries?. American psychologist, 52, 130-139.

Berson, Y., Nemanich, L.A., Waldman, D.A., Galvin, B.M., Keller, R.T. (2006). Leadership and organizational learning: A multiple levels perspective. The Leadership Quarterly, 17(6), 577-594.

Bu, N., Craig, T. J., \& Peng, T. K. (2001). Acceptance of supervisory direction in typical workplace situations: A comparison of US, Taiwanese and PRC Employees. International Journal of Cross Cultural Management, 1(2), 131-152.

Byrne, G.J., \& Bradley, F. (2007). Culture's influence on leadership efficiency: How personal and national cultures affect leadership style. Journal of Business Research, 60(2), 168-175. 
Crossan, M. M., Lane, H. W., \& White, R. E. (1999). An organizational learning framework: From intuition to institution. Academy of Management Review, 24, 522-537.

Faris, N., \& Parry, K. (2011). Islamic organizational leadership within a Western society: The problematic role of external context. The Leadership Quarterly, 22(1), 132-151

Graen, G. B., Hui, C., Wakabayashi, M., \& Wang, Z. M. (1997). Cross-cultural research alliances in organizational research: Cross-cultural partnership making in action. Cross-cultural research in industrial organizational psychology, San Francisco: Jossey Bass, 160-189.

Graen, G. B., \& Hui, C. (1999). Transcultural global leadership in the twenty-first century: Challenges and implications for development. Advances in global leadership, 1, 9-26.

Hofstede, G. (1980). Culture's consequences: International differences in work-related values, $5^{\text {th }}$ ed.. Sage Publications, Incorporated.

Jung, D.I., Chow, C., \& Wu, A. (2003). The role of transformational leadership in enhancing organizational innovation: Hypotheses and some preliminary findings. The Leadership Quarterly, 14(4-5), 525-544.

Ke, W., \& Wei, K.K. (2008). Organizational culture and leadership in ERP implementation. Decision Support Systems, 45(2), 208-218

Kim, J.H., Kim, C.S., \& Kim, J.M. (2011). Analysis of the effect of leadership and organizational culture on the organizational effectiveness of radiological technologist's working environments. Radiography, 17(3), 201-206

Kwantes, C.T., \& Boglarsky, C.A. (2007). Perceptions of organizational culture, leadership effectiveness and personal effectiveness across six countries. Journal of International Management, 13(2), 204-230.

Markham, S.E. (2010). Leadership, levels of analysis, and déjà vu: Modest proposals for taxonomy and cladistics coupled with replication and visualization. The Leadership Quarterly, 21(6), 11211143.

Menges, J.I., Walter, F., Vogel, B., \& Bruch, H. (2011). Transformational leadership climate: Performance linkages, mechanisms, and boundary conditions at the organizational level. The Leadership Quarterly, 22(5), 893-909.

Mills, D. Q. (2005). Asian and American leadership styles: How are they unique. Harvard Business School Working Knowledge.

Rajah, R., Song, Z., \& Arvey, R.D. (2011). Emotionality and leadership: Taking stock of the past decade of research. The Leadership Quarterly, 22(6), 1107-1119.

Shao, Z., Feng, Y., \& Liu, L. (2012). The mediating effect of organizational culture and knowledge sharing on transformational leadership and Enterprise Resource Planning systems success: An empirical study in China. Computers in Human Behavior, 28(6), 2400-2413.

Steyrer, J., Schiffinger, M., \& Lang, R. (2008). Organizational commitment-A missing link between leadership behavior and organizational performance?. Scandinavian Journal of Management, 24(4), 364-374.

Tsui, A.S., Zhang, Z.X., Wang, H., Xin, K.R., \& Wu, J.B. (2006). Unpacking the relationship between CEO leadership behavior and organizational culture. The Leadership Quarterly, 17(2), 113-137

Walumbwa, F.O., Mayer, D.M., Wang, P., Wang, H., Workman, K., Christensen, A.L. (2011). Linking ethical leadership to employee performance: The roles of leader-member exchange, selfefficacy, and organizational identification. Organizational Behavior and Human Decision Processes, 115(2), 204-213

Wilderom, C.P.M., van den Berg, P.T., \& Wiersma, U.J. (2012). A longitudinal study of the effects of charismatic leadership and organizational culture on objective and perceived corporate performance. The Leadership Quarterly, 23(5), 835-848.

Yuan, C.K., \& Lee, C.Y. (2011). Exploration of a construct model linking leadership types, organization culture, employees performance and leadership performance. Procedia - Social and Behavioral Sciences, 25, 123-136. 
Zehir, C., \& Erdogan, E. (2011). The association between Organizational Silence and Ethical Leadership through Employee Performance. Procedia - Social and Behavioral Sciences, 24, 13891404

Zehir, C., Ertosun, Ö. G., Zehir, S., \& Müceldili, B. (2011). The effects of leadership styles and organizational culture over firm performance: Multi-National companies in İstanbul. Procedia Social and Behavioral Sciences, 24, 1460-1474. 